\title{
Correlation between visual function, neurodevelopmental outcome, and magnetic resonance imaging findings in infants with periventricular leucomalacia
}

Giovanni Cioni, Barbara Bertuccelli, Antonio Boldrini, Raffaello Canapicchi, Barbara Fazzi, Andrea Guzzetta, Eugenio Mercuri

\begin{abstract}
Aim-To evaluate the correlation between visual function and neurodevelopmental outcome in children with periventricular leucomalacia at 1 and 3 years.

Method-Visual acuity, visual field, ocular motility, and optokinetic nystagmus were tested in 29 infants with periventricular leucomalacia by brain magnetic resonance imaging. All infants also had a structured neurological examination and a Griffiths developmental assessment.

Results-21 of the infants showed at least one abnormality of visual function. The degree of visual impairment-that is, the number of visual tests showing abnormal results-correlated well with the results on developmental assessment at both ages. Conclusion-Multivariate analysis showed that visual impairment was the most important variable in determining the neurodevelopmental scores of these infants, more than their motor disability and the extent of their lesions on magnetic resonance imaging.

(Arch Dis Child Fetal Neonatal Ed 2000;82:F134-F140)
\end{abstract}

Stella Maris Scientific Institute, Division of Child Neurology and Psychiatry, Via dei Giacinti 2, I-56018 Calambrone, Pisa, Italy

G Cioni

B Bertuccelli

R Canapicchi

B Fazzi

A Guzzetta

Neonatal Intensive Care Unit, University of Pisa

A Boldrini

Department of

Neuroradiology, S

Chiara Hospital, Pisa,

Italy

R Canapicchi

Department of

Paediatrics and

Neonatal Medicine,

Imperial College,

Hammersmith

Hospital, London, UK

E Mercuri

Correspondence to:

Dr Cioni

email: ciono@inpe.unipi.it

Accepted 13 August 1999
Keywords: vision; developmental score; magnetic resonance imaging; periventricular leucomalacia

In the last decade there has been increasing evidence that infants with periventricular leucomalacia (PVL) show a high incidence of abnormalities on tests assessing various aspects of visual function, such as eye movements, visual acuity, visual fields, and visual evoked potentials. ${ }^{1-6}$ Visual abnormalities are significantly associated with the postchiasmatic visual pathway and, in particular, optic radiations and visual cortex on magnetic resonance imaging (MRI). ${ }^{4-6}$ Abnormal visual function can already be observed in the first months of life and seems to persist at preschool and school age. ${ }^{3}$ It is also known that visual abnormalities are often associated with motor, perceptual, and global neurodevelopmental abnormalities..$^{7-10}$

The relation between visual function and neurodevelopment in children with brain lesions is not fully understood. The concomitant involvement of visual and neurodevelopmental abilities found in previous studies is not surprising, as children with visual impairment often showed extensive lesions which involved the underlying structures relevant for motor, cognitive, and visual functions. ${ }^{911}{ }^{12}$ However, a causal and direct effect of visual impairment on development may also be hypothesised. Vision plays a crucial role in early motor and cognitive learning, ${ }^{13}$ and developmental retardation is often observed in congenitally blind infants, even in the absence of brain lesions. ${ }^{14}$

The aim of this study was to evaluate the correlation between visual function and neurodevelopmental outcome in the first year of life in infants with PVL. More specifically, we aimed not only to evaluate whether developmental scores correlated with the extent of visual impairment but also, by multivariate analysis, whether such a correlation, if confirmed, could be due to other variables, such as the severity of brain lesions, rather than directly to the visual impairment.

\section{Subjects and methods}

The patients included in this research are part of a continuing follow up study of newborns with brain lesions born at the Neonatal Unit of the University Hospital of Pisa between January 1989 and December 1994. As part of this study, all the newborns with brain lesions on sequential neonatal ultrasound, performed with 5 and $7.5 \mathrm{MHz}$ probes, who present clinical neurological abnormalities at term, such as abnormal muscle tone or abnormal quality of spontaneous movements, ${ }^{15}$ are referred to the Division of Child Neurology and Psychiatry and are enrolled in a prospective clinical and MRI follow up study.

For the present research we selected all cases fulfilling the following criteria:

(a) clear signs of PVL on MRI, according to the criteria indicated in the literature ${ }^{16}{ }^{17}$;

(b) comprehensive visual assessment performed at the mean (SD) age, corrected for prematurity, of 12 (4) months;

(c) neurological and neurodevelopmental assessments performed at the same age as the visual assessment.

As the aim of this study was to evaluate cerebral visual impairment, infants who showed severe ophthalmological abnormalities (such as ROP stage III or upwards, major refraction problems, optic nerve atrophy) were excluded. Similarly, we also excluded infants with congenital diseases.

NEUROLOGICAL EXAMINATION

This was performed by using an examination based on Touwen criteria. ${ }^{18}$ The infants were classified into three groups: (1) normal; (2) mildly abnormal (mild retardation and/or 
Table 1 Grading of magnetic resonance imaging findings

\begin{tabular}{|c|c|c|c|}
\hline \multirow[t]{3}{*}{ Size of lateral ventricles } & Grade 1 & \multicolumn{2}{|c|}{ Normal size of both ventricles } \\
\hline & Grade 2 & \multicolumn{2}{|c|}{ Unilateral enlargement or bilateral mild enlargement } \\
\hline & Grade 3 & \multicolumn{2}{|c|}{ Bilateral severe enlargement } \\
\hline \multirow[t]{3}{*}{ WM abnormal signal intensity } & Grade 1 & \multicolumn{2}{|c|}{ Normal WM or only focal involvement of PV-WM } \\
\hline & Grade 2 & \multicolumn{2}{|c|}{$\begin{array}{l}\text { Diffuse involvement of PV-WM in both hemispheres or involvement of SC-WM in } \\
\text { one hemisphere }\end{array}$} \\
\hline & Grade 3 & \multicolumn{2}{|c|}{ Involvement of SC-WM in both hemispheres } \\
\hline \multirow[t]{3}{*}{ WM reduction } & Grade 1 & \multicolumn{2}{|l|}{ Not reduced } \\
\hline & Grade 2 & \multicolumn{2}{|c|}{ Reduction of PV-WM in both hemispheres or of deep WM diffusely in one hemisphere } \\
\hline & Grade 3 & \multicolumn{2}{|c|}{ Reduction of deep WM diffusely in both hemispheres } \\
\hline \multirow[t]{3}{*}{ Cysts } & Grade 1 & \multicolumn{2}{|c|}{ No cysts } \\
\hline & Grade 2 & \multicolumn{2}{|c|}{ Small cysts $(n<3)$ bilateral in PV regions or unilateral cystic lesion (small or large) } \\
\hline & Grade 3 & \multicolumn{2}{|c|}{ Bilateral multiple cysts (small or large) involving PV regions and/or deep WM } \\
\hline \multirow[t]{3}{*}{ Size of subarachnoid space } & Grade 1 & \multicolumn{2}{|c|}{ No enlargement } \\
\hline & Grade 2 & \multicolumn{2}{|c|}{ Bilateral diffuse mild enlargement or severe enlargement only in one hemisphere } \\
\hline & Grade 3 & \multicolumn{2}{|c|}{ Diffuse severe enlargement in both hemispheres } \\
\hline \multirow[t]{3}{*}{ Corpus callosum } & Grade 1 & \multicolumn{2}{|c|}{ Normal or thinning involving the posterior body } \\
\hline & Grade 2 & \multicolumn{2}{|c|}{ Thinning involving the total body } \\
\hline & Grade 3 & \multicolumn{2}{|l|}{ Diffuse thinning } \\
\hline Cortical grey matter & Grade 1 & \multicolumn{2}{|l|}{ No cortical abnormalities } \\
\hline \multirow[t]{2}{*}{ (ulegyria and cortical dysplasia) } & Grade 2 & \multicolumn{2}{|c|}{ Unilateral cortical abnormalities } \\
\hline & Grade 3 & \multicolumn{2}{|c|}{ Bilateral cortical abnormalities } \\
\hline \multirow[t]{3}{*}{ Total score } & Grade 1 & & $7-11$ \\
\hline & Grade 2 & \multirow[t]{2}{*}{ Sum of previous scores } & $12-16$ \\
\hline & Grade 3 & & $17-21$ \\
\hline \multirow[t]{3}{*}{ Visual cortex } & Grade 1 & \\
\hline & Grade 2 & Moderate impairment & \\
\hline & Grade 3 & Severe impairment & \\
\hline Optic radiations & Grade 1 & No impairment & \\
\hline & Grade 2 & Moderate impairment & \\
\hline & Grade 3 & Severe impairment & \\
\hline
\end{tabular}

WM, white matter; PV, periventricular; SC, subcortical (from Cioni $e t a l^{11}$ ).

neurological signs, but not cerebral palsy); (3) cerebral palsy with relatively normal head and trunk control; (4) cerebral palsy without head and trunk control.

VISUAL ASSESSMENT

This included the assessment of various aspects of visual function as follows.

Grating acuity - this was assessed binocularly by the Teller acuity card procedure..$^{19} 20$ This method is based on an inborn preference for a pattern (black and white gratings of different stripe widths) over a uniform field, depicted on cards with decreasing stripe widths. The location of the left/right position of the test stimulus varies randomly. An observer judges the infant's reaction as to the location of the test stimulus on the basis of eye and head movement. The threshold of acuity is taken as the finest stripe width for which the subject consistently responds correctly. Acuity values were expressed in minutes of arc (or cycles per degree) and compared with normative data reported in the literature..$^{21}$

Table 2 Clinical and neuroradiological findings

\begin{tabular}{|c|c|c|c|c|c|c|c|c|c|c|c|c|}
\hline \multirow[b]{2}{*}{ Case } & \multirow[b]{2}{*}{ Neurological outcome } & \multirow[b]{2}{*}{ US } & \multicolumn{10}{|c|}{ Magnetic resonance imaging } \\
\hline & & & $L V$ & WMS & $W M R$ & $G M$ & Cysts & $S S$ & $C C$ & Total score & $V C$ & OR \\
\hline 1 & Hemi & PVL-2 & 1 & 1 & 1 & 1 & 1 & 1 & 1 & 7 & 1 & 1 \\
\hline 2 & Norm & PVL-1 & 1 & 2 & 2 & 1 & 2 & 2 & 1 & 11 & 1 & 1 \\
\hline 3 & Dip & PVL-1 & 1 & 2 & 2 & 1 & 1 & 1 & 3 & 11 & 1 & 1 \\
\hline 4 & Reta & PVL-1 & 1 & 1 & 1 & 1 & 1 & 2 & 1 & 8 & 1 & 1 \\
\hline 5 & Dip & PVL-2 & 1 & 2 & 1 & 1 & 1 & 1 & 3 & 10 & 1 & 3 \\
\hline 6 & Reta & PVL-1 & 1 & 1 & 1 & 1 & 1 & 1 & 1 & 7 & 1 & 1 \\
\hline 7 & Hemi & PVL-1/IPE & 2 & 2 & 2 & 1 & 2 & 2 & 1 & 12 & 1 & 1 \\
\hline 8 & Dip & PVL-3 & 2 & 2 & 2 & 1 & 1 & 1 & 2 & 11 & 1 & 1 \\
\hline 9 & Dip & PVL-1 & 1 & 2 & 2 & 1 & 1 & 1 & 2 & 10 & 1 & 2 \\
\hline 10 & Reta & PVL-2 & 1 & 2 & 2 & 1 & 2 & 2 & 1 & 11 & 1 & 2 \\
\hline 11 & Reta & PVL-1 & 3 & 2 & 2 & 1 & 1 & 1 & 3 & 13 & 1 & 1 \\
\hline 12 & Dip & PVL-1 & 1 & 1 & 1 & 1 & 1 & 2 & 1 & 8 & 1 & 1 \\
\hline 13 & Dip & PVL-2 & 1 & 2 & 2 & 1 & 2 & 1 & 2 & 11 & 1 & 3 \\
\hline 14 & Dip & PVL-3 & 1 & 2 & 2 & 1 & 1 & 1 & 1 & 9 & 1 & 1 \\
\hline 15 & Dip & PVL-2 & 1 & 2 & 1 & 1 & 1 & 1 & 1 & 8 & 1 & 1 \\
\hline 16 & Dip & PVL-1 & 2 & 2 & 2 & 1 & 2 & 1 & 1 & 11 & 1 & 2 \\
\hline 17 & Dip & PVL-1 & 2 & 2 & 1 & 1 & 1 & 2 & 1 & 10 & 1 & 2 \\
\hline 18 & Dip & NA & 3 & 2 & 2 & 1 & 2 & 2 & 2 & 14 & 1 & 2 \\
\hline 19 & Reta & PVL-1 & 2 & 2 & 2 & 1 & 2 & 1 & 1 & 11 & 1 & 3 \\
\hline 20 & Reta & PVL-2 & 1 & 1 & 1 & 1 & 1 & 1 & 1 & 7 & 1 & 1 \\
\hline 21 & Dip & PVL-2 & 2 & 3 & 3 & 1 & 1 & 2 & 2 & 14 & 1 & 2 \\
\hline 22 & Tetra & PVL-3 & 3 & 2 & 2 & 1 & 1 & 2 & 2 & 13 & 1 & 3 \\
\hline 23 & Dip & PVL-3 & 2 & 2 & 2 & 1 & 1 & 2 & 2 & 12 & 1 & 2 \\
\hline 24 & Dip & PVL-1 & 3 & 3 & 3 & 1 & 2 & 2 & 3 & 17 & 1 & 1 \\
\hline 25 & Dip & PVL-1/IPE & 3 & 2 & 2 & 2 & 2 & 2 & 3 & 16 & 2 & 3 \\
\hline 26 & Tetra & PVL-3 & 3 & 2 & 2 & 1 & 3 & 1 & 3 & 15 & 1 & 3 \\
\hline 27 & Tetra & PVL-3 & 3 & 2 & 3 & 1 & 2 & 1 & 3 & 15 & 1 & 3 \\
\hline 28 & Tetra & PVL-2 & 3 & 2 & 3 & 1 & 1 & 2 & 3 & 15 & 1 & 3 \\
\hline 29 & Tetra & PVL-3 & 2 & 2 & 2 & 1 & 2 & 1 & 2 & 12 & 1 & 3 \\
\hline
\end{tabular}

Hemi, hemiplegia; Dip, diplegia; Tetra, tetraplegia; Reta, retardation; Norm, normal; PVL, periventricular leucomalacia graded as described by deVries et a $\ell^{5}$; IPE, intraparenchymatous echodensity; NA, not available; LV, lateral ventricles; WMS, white matter described by deVries $e t l^{2}$; IPE, intraparenchymatous echodensity; NA, not available; LV, lateral ventricles; WMS, white matter
abnormal signal intensity; WMR, white matter reduction; GM, grey matter; SS, subarachnoid space; CC, corpus callosum; VC, visual cortex; OR, optic radiations. 
Table 3 Results of visual and neurodevelopmental assessment

\begin{tabular}{|c|c|c|c|c|c|c|c|c|c|c|c|c|c|c|c|c|}
\hline \multirow[b]{2}{*}{ Case } & \multicolumn{7}{|c|}{ Visual findings } & \multicolumn{7}{|c|}{ Griffith DQs at 1 year } & \multicolumn{2}{|c|}{$\begin{array}{l}\text { Griffith } D Q \text { at } \\
3 \text { years }\end{array}$} \\
\hline & $\begin{array}{l}\text { Age at } \\
\text { testing }\end{array}$ & $\begin{array}{l}\text { Visual } \\
\text { acuity }\end{array}$ & $\begin{array}{l}\text { Visual } \\
\text { field }\end{array}$ & $\begin{array}{l}\text { Fix/ } \\
\text { following }\end{array}$ & Strabismus & $O K N$ & $\begin{array}{l}\text { Total } \\
\text { score }\end{array}$ & $\begin{array}{l}\text { Age at } \\
\text { testing }\end{array}$ & Locomotor & $\begin{array}{l}\text { Personal- } \\
\text { social }\end{array}$ & $\begin{array}{l}\text { Hearing- } \\
\text { speech }\end{array}$ & $\begin{array}{l}\text { Hand-eye } \\
\text { coordination }\end{array}$ & Performance & General & $\begin{array}{l}\text { Age at } \\
\text { testing }\end{array}$ & General \\
\hline 1 & 11 & $\mathrm{~N}$ & $\mathrm{~N}$ & $\mathrm{~N}$ & - & $\mathrm{N}$ & 0 & 14 & 84 & 107 & 93 & 96 & 104 & 97 & 36 & 102 \\
\hline 2 & 11 & $\mathrm{~N}$ & $\mathrm{~N}$ & $\mathrm{~N}$ & - & $\mathrm{N}$ & 0 & 12 & 109 & 95 & 91 & 87 & 87 & 94 & 36 & 94 \\
\hline 3 & 8 & $\mathrm{~N}$ & $\mathrm{~N}$ & $\mathrm{~N}$ & - & $\mathrm{N}$ & 0 & 12 & 81 & 96 & 100 & 92 & 100 & 94 & & \\
\hline 4 & 13 & $\mathrm{~N}$ & $\mathrm{~N}$ & $\mathrm{~N}$ & - & $\mathrm{N}$ & 0 & 13 & 77 & 96 & 104 & 92 & 92 & 92 & 45 & 93 \\
\hline 5 & 14 & $\mathrm{~N}$ & $\mathrm{~N}$ & $\mathrm{~N}$ & - & $\mathrm{N}$ & 0 & 15 & 80 & 90 & 93 & 90 & 87 & 88 & 39 & 78 \\
\hline 6 & 14 & $\mathrm{~N}$ & $\mathrm{~N}$ & $\mathrm{~N}$ & - & $\mathrm{N}$ & 0 & 14 & 75 & 93 & 93 & 89 & 85 & 87 & 31 & 102 \\
\hline 7 & 14 & $\mathrm{~N}$ & $\mathrm{~N}$ & $\mathrm{~N}$ & - & A & 1 & 14 & 93 & 96 & 107 & 110 & 100 & 101 & 34 & 84 \\
\hline 8 & 10 & $\mathrm{~N}$ & $\mathrm{~N}$ & $\mathrm{~N}$ & - & A & 1 & 10 & 85 & 100 & 90 & 90 & 100 & 93 & 31 & 101 \\
\hline 9 & 14 & $\mathrm{~N}$ & $\mathrm{~N}$ & $\mathrm{~N}$ & - & A & 1 & 14 & 89 & 89 & 82 & 85 & 89 & 87 & 31 & 95 \\
\hline 10 & 14 & $\mathrm{~N}$ & $\mathrm{~N}$ & $\mathrm{~N}$ & - & A & 1 & 13 & 69 & 89 & 100 & 89 & 80 & 85 & & \\
\hline 11 & 12 & $\mathrm{~N}$ & $\mathrm{~N}$ & $\mathrm{~N}$ & + & $\mathrm{N}$ & 1 & 12 & 88 & 93 & 117 & 87 & 92 & 95 & 37 & 93 \\
\hline 12 & 9 & $\mathrm{~N}$ & $\mathrm{~N}$ & $\mathrm{~N}$ & + & $\mathrm{N}$ & 1 & 11 & 71 & 81 & 77 & 73 & 73 & 75 & 34 & 65 \\
\hline 13 & 15 & $\mathrm{~N}$ & $\mathrm{~N}$ & $\mathrm{~N}$ & + & $\mathrm{N}$ & 1 & 16 & 84 & 62 & 69 & 66 & 56 & 67 & & \\
\hline 14 & 12 & $\mathrm{~N}$ & $\mathrm{~N}$ & $\mathrm{~N}$ & + & A & 2 & 12 & 69 & 100 & 100 & 96 & 96 & 92 & 36 & 85 \\
\hline 15 & 16 & $\mathrm{~N}$ & $\mathrm{~N}$ & $\mathrm{~N}$ & + & A & 2 & 12 & 33 & 100 & 112 & 83 & 83 & 82 & 36 & 95 \\
\hline 16 & 14 & $\mathrm{~N}$ & $\mathrm{~N}$ & $\mathrm{~N}$ & + & A & 2 & 14 & 58 & 79 & 75 & 75 & 60 & 69 & 31 & 91 \\
\hline 17 & 15 & A & $\mathrm{N}$ & $\mathrm{N}$ & + & $\mathrm{N}$ & 2 & 13 & 77 & 92 & 92 & 89 & 89 & 88 & & \\
\hline 18 & 15 & A & $\mathrm{N}$ & $\mathrm{N}$ & + & $\mathrm{N}$ & 2 & 15 & 47 & 70 & 77 & 50 & 53 & 59 & 39 & 75 \\
\hline 19 & 11 & A & $\mathrm{N}$ & $\mathrm{N}$ & + & A & 3 & 10 & 90 & 110 & 85 & 85 & 115 & 97 & 30 & 100 \\
\hline 20 & 10 & A & $\mathrm{N}$ & $\mathrm{N}$ & + & A & 3 & 10 & 80 & 80 & 75 & 75 & 75 & 77 & 36 & 95 \\
\hline 21 & 15 & A & $\mathrm{BN}$ & A & + & $\mathrm{N}$ & 4 & 15 & 50 & 76 & 76 & 66 & 71 & 68 & & \\
\hline 22 & 8 & A & $\mathrm{BN}$ & $\mathrm{N}$ & + & A & 4 & 11 & $<20$ & 77 & 77 & 55 & 45 & 54 & & \\
\hline 23 & 10 & A & $\mathrm{BN}$ & A & + & A & 5 & 11 & 64 & 91 & 91 & 86 & 73 & 81 & & \\
\hline 24 & 12 & A & $\mathrm{BN}$ & A & + & A & 5 & 13 & 46 & 77 & 81 & 69 & 62 & 67 & 34 & 59 \\
\hline 25 & 12 & A & RL & A & + & A & 5 & 8 & 65 & 50 & 42 & 38 & 38 & 47 & 47 & 66 \\
\hline 26 & 13 & A & $\mathrm{BN}$ & A & + & A & 5 & 8 & 25 & 57 & 71 & 43 & $<20$ & 42 & 30 & 32 \\
\hline 27 & 12 & A & $\mathrm{BN}$ & A & + & A & 5 & 14 & 23 & 28 & 43 & 39 & 39 & 34 & 40 & 41 \\
\hline 28 & 16 & A & $\mathrm{BN}$ & A & + & A & 5 & 16 & $<20$ & 37 & 47 & 37 & $<20$ & 28 & & \\
\hline 29 & 12 & A & $\mathrm{BN}$ & A & + & A & 5 & 12 & $<20$ & 33 & 54 & 25 & $<20$ & 26 & & \\
\hline
\end{tabular}

DQ, developmental quotient; BN, bilateral narrow; RL, right loss; N, normal; A, abnormal; +, present; -, absent.

Visual field - its size was assessed using kinetic perimetry by the technique described in detail elsewhere. ${ }^{1819}$ The apparatus consists of two $4 \mathrm{~cm}$ wide black metal strips, mounted perpendicularly to each other and bent to form two arcs, each with a radius of $40 \mathrm{~cm}$. The perimeter is placed in front of a black curtain, concealing the observer, who can watch the infant's eye and head movements through a peep hole. The infant is held in the centre of the arc perimeter, with the chin supported. During central fixation of a $6^{\circ}$ diameter white ball, an identical target is moved from the periphery towards the fixation point along one of the arcs of the perimeter at a velocity of around $3 \%$ s. Eye and head movements towards the peripheral ball are used to estimate the outline of the visual fields. Normative data for full term and preterm infants are available. ${ }^{21} 22$ Horizontal optokinetic nystagmus (OKN) - this was elicited by moving a large piece of paper at a distance of $40 \mathrm{~cm}$ in front of the infant's face, at a velocity of about $15 \%$ s. The paper is covered with black and white dots of $1 \mathrm{~cm}^{2}$. The number of saccades in response to left side stimulation is judged and compared with that of right side stimulation. Normally, binocular $\mathrm{OKN}$ is symmetrical from birth onwards, whereas monocular OKN (not systematically tested in this study) shows a better response to stimulation in a temporonasal direction up to about 3 to 6 months of corrected age.

Oculomotor behaviour (following and fixation) and strabismus - any abnormality of eye contact, spontaneous nystagmus, fixation and following in all directions, and convergence movements is also noted. Eye alignment was tested by commonly used orthoptic techniques, such as the cover test.
Each test of visual function was scored on a two point scale $(0=$ normal, $1=$ abnormal $)$. A visual function score was given to each infant on the basis of the number of impaired items. Scores ranged from 0 (no item impaired) to 5 (all items impaired).

DEVELOPMENTAL ASSESSMENT

This was assessed using the Griffiths developmental scales. ${ }^{23}$ General developmental quotients (DQs) and, separately, the DQ of each subscale (locomotor, personal-social, hearingspeech, hand-eye co-ordination, and performance) were obtained. Scores were classified as normal (85 or above), borderline (84-71), or abnormal (70 or below). The test was performed at about 1 year of age (range 8-16 months), and a follow up assessment was also performed at around 3 years of age (range 30-47 months).

MAGNETIC RESONANCE IMAGING

Brain MRI studies were performed under sedation using a $0.5 \mathrm{~T}$ system in sequence spin-echo. T1, proton density, and T2 weighted images were obtained in the axial, coronal, and sagittal planes with sections of 5 $\mathrm{mm}$. The images were assessed retrospectively by a neuroradiologist (RC) and separately by a child neurologist (GC), unaware of the prenatal and perinatal histories or of the clinical evaluations. MRI findings were scored according to two different classifications used in our previous studies on PVL ${ }^{1124}$ (table 1).

\section{Extent of the lesion}

The following items were scored: size of lateral ventricles, evidence and extension of white matter damage (as shown by areas of prolonged $\mathrm{T} 1$ and/or T2 relaxation) and of white matter 

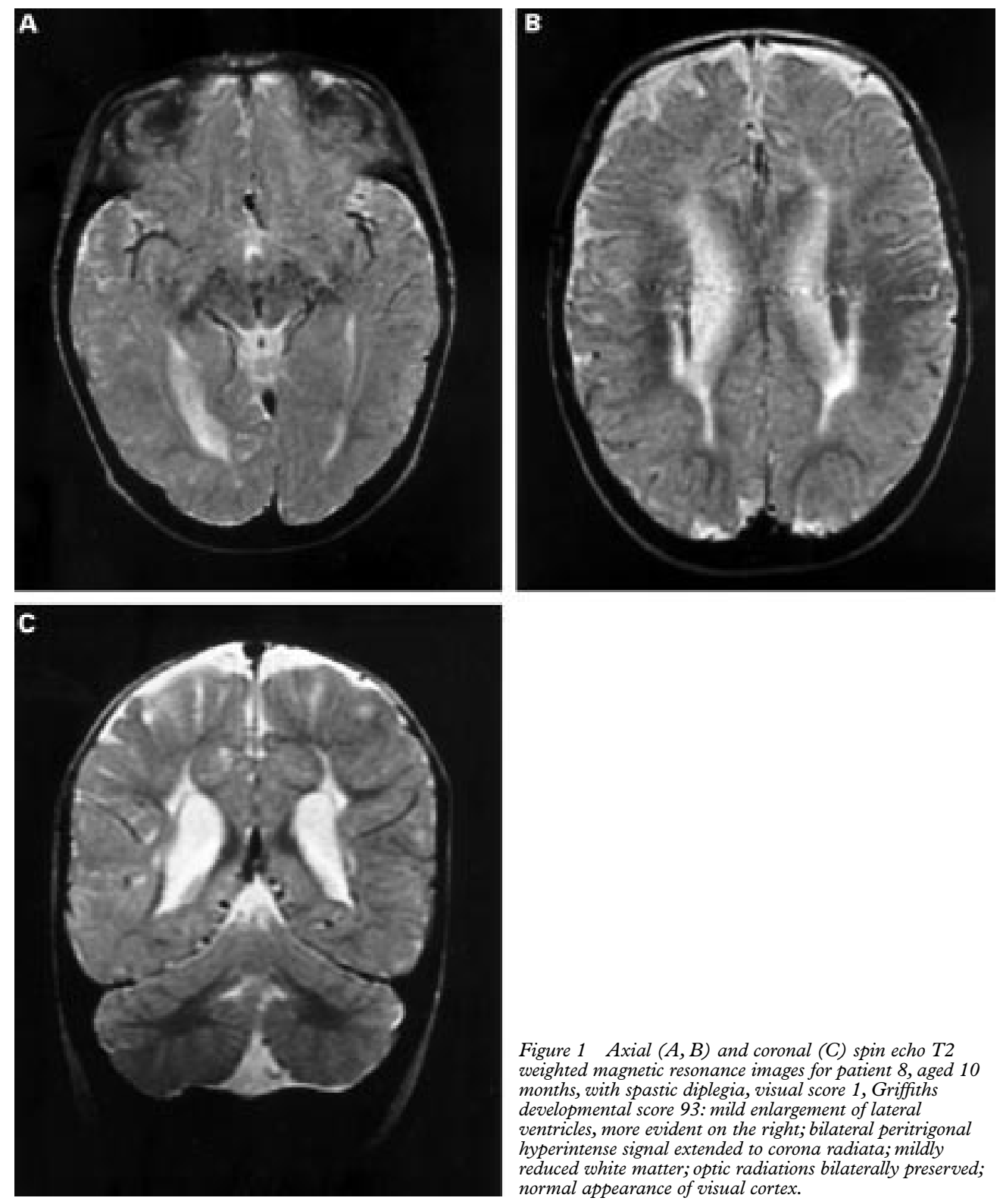

Figure 1 Axial $(A, B)$ and coronal $(C)$ spin echo $T 2$ weighted magnetic resonance images for patient 8 , aged 10 months, with spastic diplegia, visual score 1, Griffiths developmental score 93: mild enlargement of lateral ventricles, more evident on the right; bilateral peritrigonal hyperintense signal extended to corona radiata; mildly reduced white matter; optic radiations bilaterally preserved; normal appearance of visual cortex.

loss (as shown by abnormal infolding of cerebral gyri and sulci), thinning of corpus callosum, evidence and size of cystic areas (as shown by areas of hypointensity on $\mathrm{T} 1$ and proton density weighted images and hyperintensity on T2 weighted images), size of the subarachnoid space, and abnormalities of cortical grey matter. Each item was scored on a three grade scale, with score 3 indicating the most severe MRI abnormalities. The scores of the seven items were summed to obtain a total score for each infant. The total scores were also classified on a three grade scale.

Severity of the lesions in optic radiation and visual cortex (striate, parastriate, and peristriate areas)

Three degrees of impairment were scored: 1, no impairment; 2, moderate impairment; 3, severe impairment. The left and right sides were graded separately. In the few cases in which side differences were found, the most severe scores were taken.
STATISTICAL ANALYSIS

Correlation analysis was performed by the Kendall correlation test (tau-b coefficient). A multiple regression analysis was conducted to assess effect of visual impairment, motor outcome, and MRI findings on cognitive development at 1 year. The correlation between DQs at 1 and 3 years was tested by the Spearman test.

Although the aim of this study was to correlate visual and developmental findings at the same age (1 year), we also correlated both visual and cognitive findings at 1 year with developmental scores obtained after 30 months.

\section{Results}

Twenty nine infants fulfilled the inclusion criteria. Their gestational age at birth ranged from 27 to 36 weeks (mean (SD) 31 (2.8) weeks). Mean (SD) age at testing (corrected for prematurity) was 13 (2.1) months (range 

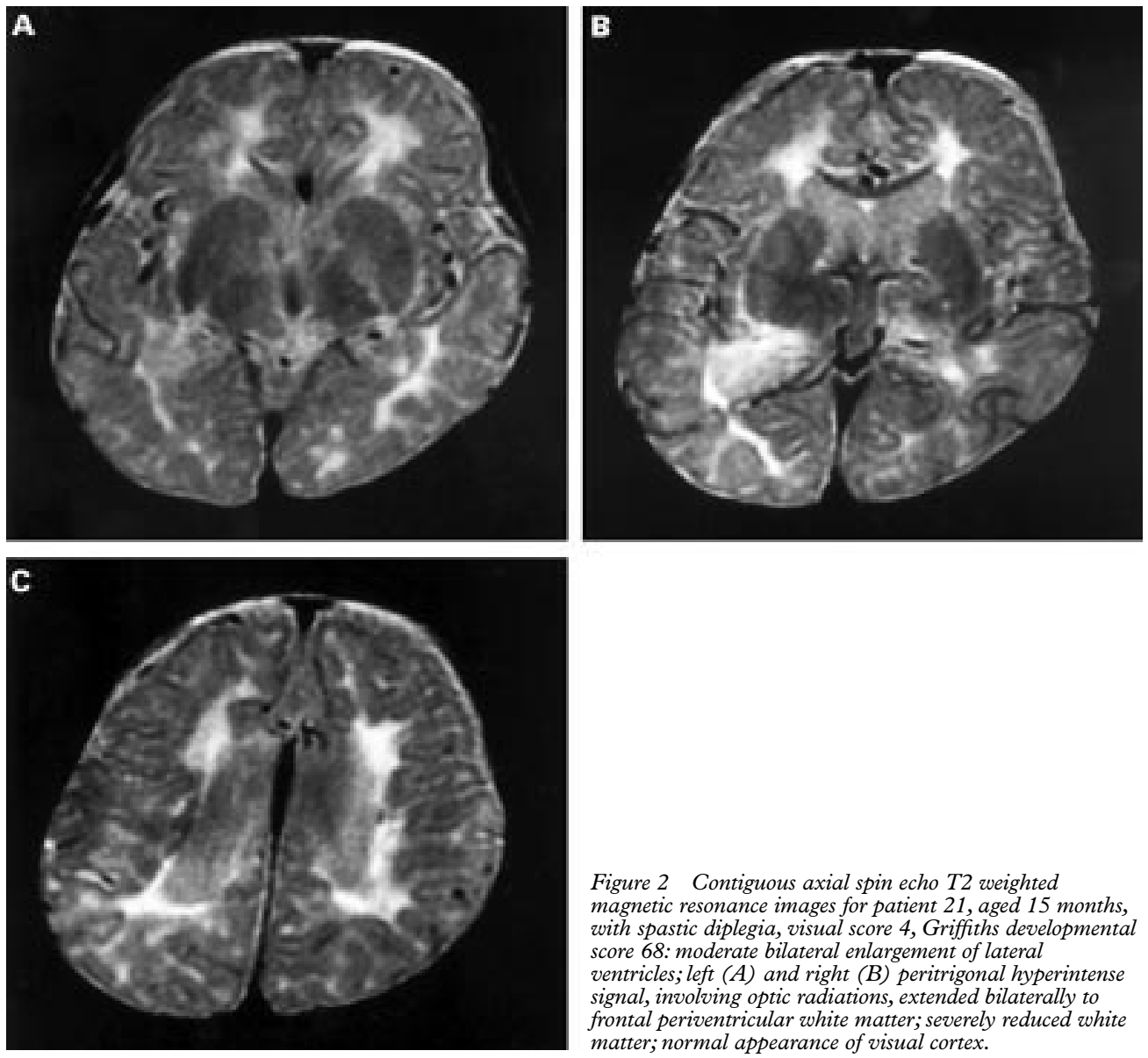

8-16). Table 2 summarises the results of all infants tested. Cranial ultrasound results were available in 28 of the 29 infants studied. According to the classification suggested by de Vries et al, ${ }^{25} 13$ infants had grade 1 PVL, eight had grade 2 , and seven grade 3 . Table 2 gives the details of ultrasound findings.

\section{NEUROLOGICAL EXAMINATION}

One case showed normal and six mildly delayed motor development while the remaining 22 subjects had cerebral palsy. Seventeen infants showed relatively normal head and trunk control (15 diplegic and two hemiplegic cases), which was lacking in the other five infants (all tetraplegic cases).

VISUAL ASSESSMENT

Severe fixation and following disorders were present in eight of the 29 infants and strabismus in 19. Abnormal grating acuity was
Figure 2 Contiguous axial spin echo T2 weighted magnetic resonance images for patient 21 aged 15 months, with spastic diplegia, visual score 4, Griffiths developmental score 68: moderate bilateral enlargement of lateral ventricles; left $(A)$ and right $(B)$ peritrigonal hyperintense signal, involving optic radiations, extended bilaterally to frontal periventricular white matter; severely reduced white matter; normal appearance of visual cortex.

found in 13, reduced visual field in nine, and OKN abnormalities in 17 .

Six infants had a visual function score of 0 (all the items were normal), seven had a score of 1 , and five had a score of 2 ; two had a score of 3 , and the other two a score of 4 . The remaining seven infants had a score of 5 (all the items abnormal). Table 3 details the visual assessment.

DEVELOPMENTAL ASSESSMENT

The global DQs in the cohort at 1 year ranged subjects had a normal DQ, four fell in the borderline range (70-84), and 11 had abnormal DQ $(<70)$. Table 3 shows results obtained in each subscale.

The global DQ at follow up was available in 20 of the 29 infants. This ranged from 32 to 102 (mean DQ = 82). from 26 to 101 (mean DQ = 74.7). Fourteen

Table 4 Correlation between Griffiths developmental quotients (DQs) and visual function score, motor, and magnetic resonance imaging (MRI) scores (all subjects included $n=29$ )

\begin{tabular}{lllllll}
\hline & \multicolumn{2}{c}{ Griffiths $D Q s$} & & & \\
\cline { 2 - 6 } & Locomotor & Personal-social & Hearing-speech & $\begin{array}{l}\text { Eye-hand } \\
\text { coordination }\end{array}$ & Performance & Global \\
\hline Visual function score (0-5) & -0.53 & -0.48 & -0.50 & -0.60 & -0.54 & -0.58 \\
Motor score (1-3) & $\mathrm{p}=0.000$ & $\mathrm{p}=0.001$ & $\mathrm{p}=0.000$ & $\mathrm{p}=0.000$ & $\mathrm{p}=0.000$ & $\mathrm{p}=0.000$ \\
MRI score (1-3) & -0.55 & -0.46 & -0.44 & -0.43 & -0.47 & -0.53 \\
& $\mathrm{p}=0.000$ & $\mathrm{p}=0.003$ & $\mathrm{p}=0.004$ & $\mathrm{p}=0.005$ & $\mathrm{p}=0.002$ & $\mathrm{p}=0.000$ \\
& -0.38 & -0.48 & -0.30 & -0.46 & -0.47 & -0.43 \\
& $\mathrm{p}=0.02$ & $\mathrm{p}=0.002$ & $\mathrm{p}=0.054$ & $\mathrm{p}=0.004$ & $\mathrm{p}=0.003$ & $\mathrm{p}=0.006$ \\
\hline
\end{tabular}

Kendall tau-b. 
Table 5 Correlation between Griffiths developmental quotients (DQs) and visual function score, motor, and magnetic resonance imaging (MRI) scores (tetraplegic subjects excluded $n=24$ )

\begin{tabular}{|c|c|c|c|c|c|c|}
\hline & \multicolumn{6}{|c|}{ Griffiths $D Q s$} \\
\hline & Locomotor & Personal-social & Hearing-speech & $\begin{array}{l}\text { Eye-hand } \\
\text { coordination }\end{array}$ & Performance & Global \\
\hline Visual function score $(0-5)$ & $\begin{array}{l}-0.38 \\
p=0.01\end{array}$ & NS & $\begin{array}{l}-0.35 \\
p=0.02\end{array}$ & $\begin{array}{l}-0.47 \\
p=0.003\end{array}$ & $\begin{array}{l}-0.36 \\
p=0.02\end{array}$ & $\begin{array}{l}-0.43 \\
p=0.006\end{array}$ \\
\hline Motor score $(1-3)$ & NS & NS & NS & NS & NS & NS \\
\hline MRI score $(1-3)$ & NS & NS & NS & NS & NS & NS \\
\hline
\end{tabular}

Kendall tau-b.

MAGNETIC RESONANCE IMAGING

Table 2 shows details of the MRI findings. The total score, summating the results of the individual items assessing the extent of the lesions, ranged from 7 to 17 . When optic radiation and visual cortex were assessed, 16 infants had involvement of the optic radiation. One of the 16 also showed involvement of the visual cortex.

Figures 1 and 2 show magnetic resonance images for cases 8 and 21 respectively.

CORRELATION BETWEEN VISUAL FUNCTION AND MRI FINDINGS

There was a significant correlation between visual function score and size of lateral ventricles (tau-b $=0.63 ; \mathrm{p}<0.000)$, white matter damage (tau-b $=0.40 ; \mathrm{p}=0.01$ ), white matter loss (tau-b $=0.48 ; \mathrm{p}=0.003$ ), and corpus callosum (tau-b =0.35; $\mathrm{p}=0.03$ ).

A very high correlation coefficient was also found with optic radiation (tau-b $=0.76$; $\mathrm{p}<0.000)$. Visual cortex was not included in this kind of analysis because only one infant of our sample showed abnormalities; this infant presented severe visual impairment in all the items evaluated, as well as mental retardation and severe diplegia.

CORRELATION BETWEEN VISUAL FUNCTION AND DEVELOPMENTAL SCORES

There was a significant correlation between visual impairment and general DQ (tau $=0.58 ; \mathrm{p}=0.000) ;$ the correlation also reached significance for all subscale DQs (table 4).

CORRELATION BETWEEN BRAIN LESIONS AND MOTOR ABILITY AND DEVELOPMENTAL SCORES Both brain lesions and motor impairment also showed a significant correlation with developmental scores (tau $=-0.53, p=0.000$ and tau $=0.43$ and $\mathrm{p}=0.000$, respectively). Table 4 shows details of the correlation with the subscale DQs.

DIRECT COMPARISON OF THE INFLUENCE OF VISUAL, MOTOR, AND MRI FINDINGS ON DEVELOPMENT ASSESSMENT

To examine the influence of visual, motor, and MRI impairment on developmental scores, we also did a multiple regression analysis (stepwise method), which always indicated the visual deficit to be the most important variable in determining cognitive performances of our sample $(\mathrm{F}=40.9, \mathrm{p}<0.000)$; motor impairment entered as the second variable $(F=32.9$, $\mathrm{p}<0.000$ ), while brain lesions, as detected by MRI, did not reach significance.
The results were quite different when tetraplegic infants were not included in the sample. Both the global DQ and the subscale DQ remained correlated with visual impairment (except for personal-social DQ) but not with motor outcome and MRI findings. On multivariate analysis, visual function was the only variable to reach significance $(\mathrm{F}=12.8$, $\mathrm{p}=0.002)($ table 5).

\section{CORRELATION BETWEEN EARLY AND LATE} ASSESSMENT

There was a significant correlation between visual impairment at 1 year and general DQ at 3 years $($ tau-b $=0.40 ; p=0.02)$. Moreover the DQs at the two assessments were significantly correlated $(r=0.65 ; \mathrm{p}=0.002)$.

\section{Discussion}

Our results show a high incidence of abnormalities in various aspects of visual function, such as grating acuity, ocular motility, visual field, and OKN in infants with PVL. Twenty three out of 29 of our children had at least one abnormality on one of these tests, and more than $50 \%$ had multiple abnormalities. These are higher than in previous studies, ${ }^{1569}$ and the difference may be explained by the different inclusion criteria used. In our study, only infants with PVL on ultrasound examination who had overt clinical signs at term underwent MRI, and those with PVL who had a normal neurological examination at term were not enrolled in the prospective clinical and imaging follow up study. The aim of this study, however, was not to replicate previous studies reporting the incidence of visual abnormalities in a population of infants with PVL, ${ }^{59}$ but to evaluate whether visual abnormalities at 1 year, if present, were associated with the extent of the lesions on MRI and with neurocognitive abnormalities assessed at the same time.

In agreement with previous studies, ${ }^{4624}$ we found a strong association between the degree of visual impairment and the involvement of optic radiation on MRI.

We were also able to show a significant correlation between visual function and neurodevelopmental quotients at 1 year. The infants with normal visual function had normal cognitive performances, while those with the most severe visual impairment also had the lowest DQ. The correlation was significant not only with the developmental assessment performed at 1 year, but also with that performed after 2 years of age. These results confirm our previous findings in full term infants with hypoxic-ischaemic encephalopathy, ${ }^{12}$ in whom 
we also found a strong correlation between visual function and DQ.

The only study to report an association between early visual and developmental abnormalities in preterm infants with PVL is by Eken et al. ${ }^{9}$ Their findings, however, cannot be easily compared with ours, as they also included preterm infants with other types of brain lesion, and visual acuity was the only measure of visual function assessed.

Our study has also highlighted the importance of assessing various aspects of visual function, as these may play an important role in global development.

In this study we were also interested to evaluate whether the low developmental scores could be mainly due to the severity of the brain lesions or motor impairment, rather than to a direct effect of the visual impairment. The values of the correlation coefficients, as well as the results of multiple regression analysis in our cohort, suggest that visual function is crucial per se in the early development of these children. This finding is not surprising and is in agreement with previous studies, ${ }^{13}{ }^{14}$ indicating the important role played by vision in the early phases of infant development.

Although in this study the correlation between visual function and DQ was significant, some exceptions were observed. For example, cases 12 and 13 had low DQs, despite normal visual function and a mild strabismus. In contrast, other infants had a DQ within the normal range for age, but showed a strabismus associated with asymmetrical OKN (case 14) or abnormal visual acuity (cases 17 and 19). These results can be explained by the fact that, although vision plays an important role in cognitive development, the latter is a complex and multifactorial event. Other factors, related partly to biological structure of each individual (including the presence of brain lesions) and partly to environmental conditions, will also influence the outcome.

In conclusion, our findings confirm the importance of a comprehensive assessment of infants with PVL. Further studies are also needed, including other aspects of cortical visual function such as orientation-reversal visual evoked potentials, ${ }^{26}{ }^{27}$ to evaluate the relation between early abnormalities of visual function and cognitive and perceptual motor abilities at school age. Early detection of impaired visual function may permit these infants to be enrolled in early intervention programmes, which can improve their visual outcome. ${ }^{28}$ Longitudinal studies are needed to evaluate the plasticity of the central visual areas after early brain damage and the possible role of the environment in brain reorganisation.

This work was supported by grant RC 1/98 from the Italian Ministry of Health. The authors gratefully acknowledge the contribution of Jackie Van Hof-van Duin, Carlo Romano, and Michele Coluccini to the visual assessments, and Paola B Paolicelli to the neurological examinations.

1 Scher MS, Dobson V, Carpenter NA, Guthrie RD. Visual and neurological outcome of infants with periventricular leukomalacia. Dev Med Child Neurol 1994;31:353-65.
2 Eken P, de Vries LS, van Nieuwenhuizen O, Schalij-Delfos N, Reits D, Spekreijse H. Early predictors of cerebral visual impairment in infants with cystic leukomalacia. Neuropediatrics 1996;27:16-25.

3 Jacobson L, Ek U, Fernell E, Flodmark O, Broberger U. Visual impairment in preterm children with periventricular leukomalacia: visual, cognitive and neuropaediatric characteristics related to cerebral imaging. Dev Med Child Neurol 1996;38:724-35.

4 Uggetti C, Egitto MG, Fazzi E, et al. Cerebral visual impairment in periventricular leukomalacia: MR correlation. AfNR Am f Neuroradiol 1996;17:979-85.

5 Cioni G, Fazzi B, Coluccini M, et al. Cerebral visual impairment in preterm infants with periventricular leukomalacia. Pediatr Neurol 1997;17:331-8.

6 Lanzi G, Fazzi E, Uggetti C, et al. Cerebral visual impairment in periventricular leukomalacia. Neuropediatrics 1998;29:145-50.

7 van Hof-van Duin J, Cioni G, Bertuccelli B, et al. Visual outcome at 5 years of newborn infants at risk of cerebral visual impairment. Dev Med Child Neurol 1998;40:302-9.

8 Koeda T, Takeshita K. Visuo-perceptual impairment and cerebral lesions in spastic diplegia with preterm birth. Brain Dev 1992;14:239-44.

9 Eken P, de Vries LS, van der Graaf Y, Meiners LC, van Nieuwenhuizen O. Haemorragic-ischaemic lesions of the neonatal brain: correlation between cerebral visual impairment, neurodevelopmental outcome and MRI in infancy. Dev Med Child Neurol 1995;37:41-55.

10 Jongmans M, Mercuri E, Henderson S, de Vries L, Sonksen P, Dubowitz L. Visual functions of prematurely born children with and without perceptual-motor difficulties. Early Hum Dev 1996;45:73-82.

11 Cioni G, Di Paco C, Bertuccelli C, Paolicelli PB, Canapicchi R. MRI findings and sensorimotor development in infants with bilateral spastic cerebral palsy. Brain Dev 1997;19:245-53.

12 Mercuri E, Haataja L, Guzzetta A, et al. Visual function in term infants with hypoxic-ischaemic insults: correlation with neurodevelopment at 2 years of age. Arch Dis Child Fetal Neonatal Ed 1999;80:F99-104.

13 Shumway-Cook S, Woollacott M. Motor control: theory and practical applications. New York: Williams and Wilkins, 1995:143-68

14 Tröster H, Hecker W, Brambring M. Longitudinal study of gross-motor development in blind infants and preschoolers. Early Child Development and Care 1994;104:61-78.

15 Cioni G, Ferrari F, Einspieler C, et al. Comparison between observation of spontaneous movements and neurologic observation of spontaneous movements and neurologic
examination in preterm infants. $\mathcal{F}$ Pediatr 1997;130:70411.

16 Cioni G, Bartalena L, Biagioni E, et al. Neuroimaging and functional outcome of neonatal leukomalacia. Behav Brain Res 1992;49:7-19.

17 de Vries LS, Eken P, Groenendaal F, et al. Correlation between the degree of periventricular leukomalacia diagnosed using cranial ultrasound and MRI later in infancy in children with cerebral palsy. Neuropediatrics infancy in child

18 Touwen BCL. Neurological development in infancy. Clinics in developmental medicine. Vol 58. London: Heinemann, 1976.

19 McDonald MA, Dobson V, Sebris SL, Baitch L, Varner D, Teller DY. The acuity card procedure: a rapid test of infant acuity. Invest Ophthalmol Vis Sci 1985;26:1158-62.

20 Mohn G, Van Hof-van Duin J, Fetter WPF, Groot de L, Hage $M$. Acuity assessment of non-verbal infants and children: clinical experience with the acuity card procedure. Dev Med Child Neurol 1988;30:232-44.

21 van Hof-van Duin J, Heersema DJ, Groenendaal F, Baerts W, Fetter WPF. Visual field and grating acuity development in low-risk preterm infants during the first $21 / 2$ years after terms. Behav Brain Res 1992;49:115-22.

22 Mohn G, van Hof-van Duin J. Development of the binocular and monocular visual field during the first year of life. Clinical Visual Sciences 1986;1:51-64.

23 Griffiths, R. The abilities of babies: a study in mental measurement. London: University of London Press, 1954.

24 Cioni G, Fazzi B, Ipata AE, Canapicchi R, Van Hof-Van Duin J. Correlation between cerebral visual impairment and MR imaging in children with neonatal encephalopathy. Dev Med Child Neurol 1996;38:120-32.

25 de Vries LS, Eken P, Dubowitz LMS. The spectrum of leukomalacia using cranial ultrasound. Behav Brain Res 1992;49:1-6.

26 Braddick OJ, Wattam-Bell J, Atkinson J. Orientation-specific cortical responses develop early in infancy. Nature 1986;320:617-19.

27 Mercuri E, Braddick O, Atkinson J, et al. Orientationreversal and phase-reversal visual evoked potentials in fullterm infants with brain lesions: a longitudinal study. Neuropediatrics 1998;29:169-14.

28 Sonksen PM, Petrie A, Drew KJ. Promotion of visual development of severely visually impaired babies: evaluation of a developmentally based program. Dev Med Child Neurol 1991;22:320-35. 